\title{
- Impact of Female's Height on Waiting Time to the First Conception: A Semi Parametric Approach
}

\author{
A. K. Tiwari, Brijesh P. Singh, Shivam Mishra \\ Department of Statistics, Institute of Science, Banaras Hindu University, Varanasi-221005, Uttar Pradesh, India.
}

ection: Healthcare

ISI Impact Factor

(2019-20): 1.628

IC Value (2019): 90.81 $\operatorname{SJIF}(2020)=7.893$

(c) (i) (3)

Copyright@IJCRR

\section{ABSTRACT}

Background: The waiting time to the first conception plays a significant role in the determination of the fertility level of the society. It is not possible to have a direct observation of waiting time, so the waiting time is obtained from birth interval data. It holds an important place in infertility studies because the first birth interval is free from post-partum amenorrhea (PPA) and there is less chance to use any contraception. In past studies, it has been identified that different factors contribute to explaining the length of the first birth interval.

Objective: In this paper, an attempt has been done to know the impact of a new factor i.e. female's height on waiting time to the first conception.

Material \& Methods: Cox's proportional hazard model is used for this analysis. The data has been taken from the National Family Health Survey (NFHS) of Uttar Pradesh.

Results: It has been observed that along with other factors, there is a significant impact of females' height on waiting time to the first conception. The female has a height of more than $150.0 \mathrm{~cm}$ is found significantly 6 per cent more likely to get conception earlier than the female having a height less than or equal to $150.0 \mathrm{~cm}$.

Key Words: Waiting time to conception, First birth interval, Female height, Demographic and socioeconomic factors, NFHS, Cox's proportional hazard

\section{INTRODUCTION}

Fertility is the liable factor for the biological replacement and maintenance of the species in the world since every culture replenishes itself and grows through the process of fertility. Hence, the study and analysis of human fertility possess the utmost importance in population studies. In the context of population dynamics, it is considered as a vital component of population change since it provides important insights into the reproductive behaviour, action, and attitude of females which is regulated by several biological, psychological, social, economic, cultural, geographical, health and other environmental factors. That is the reason behind the altered fertility patterns found from one place to another. In Indian society, several studies have been carried out to investigate the differences in fertility among states and the factors that affect fertility rates frequently. ${ }^{1-9}$ Literature provides several indicators for analyzing the pattern and level of fertility.
The waiting time to conception is one of the important indicators of the actual performance of fertility. Among all waiting times, the waiting time to the first conception plays a significant role in the determination of the fertility level of the society. It is not possible to have a direct observation of waiting time, hence the birth interval analysis has been used to determine these variables as well as the pace and magnitude of fertility in the population. There are mainly four types of birth intervals that propose an exciting and productive space for scientific research in demography i.e. first birth interval, closed birth interval, forward birth interval, and straddling birth interval. To get information for waiting time, nine months have been subtracted from the duration of the birth interval.

In some past studies, it has been identified that different factors contribute to the length of the first birth interval. Nath et al. have estimated the net effect of each explanatory variable

\section{Corresponding Author:}

Shivam Mishra, Research Scholar, Department of Statistics, Institute of Science, Banaras Hindu University, Varanasi-221005, India. E-mail: shivam.stats@outlook.com

ISSN: 2231-2196 (Print)

Received: 22.03 .2021
ISSN: 0975-5241 (Online)

Revised: 02.06 .2021
Accepted: 12.08 .2021
Published: 01.12 .2021 
which affects the duration of first birth interval in Indian society by using multivariate hazards regression techniques. ${ }^{10,11}$ The first birth interval is free from post-partum amenorrhea (PPA) and there is less chance to use any contraception before the first conception, especially in traditional Indian society. Thus, the duration between marriage and first birth is weighed as an actual determinant of fertility analysis because it represents the actual reproductive behaviour of a female if the female is sufficiently mature enough at the time of marriage. Since not only the biological and psychological maturity is enough to get a conception and reproductive success but also physiological maturity is important. Hence, a question has been struck out whether reproductive success is regulated by the physical stature of females or not.

Some studies have been carried out in western societies to analyze the relationship between the physical compositions with the few basic parameters of fertility and survival of children among females. ${ }^{12-14}$ These studies established that the fertility of females is positively associated with the physical composition of females. Therefore, in this study, an attempt has been made to know the impact of some socioeconomic and demographic factors on waiting time to the first conception. Authors have also assumed one anthropometric measure i.e. female height having a relationship to the waiting time to the first conception and measuring the impact of height on waiting time to the first conception in presence of some selected socioeconomic and demographic factors.

\section{MATERIALS AND METHODS}

The present study has been done by using several sociodemographic variables such as place of residence, religion, caste, wealth index, educational level, family structure, and age at first birth along with the height of females to identify the association with various fertility parameters. The sociodemographic and anthropometric information of married females has been obtained from the three phases of the $\mathrm{Na}$ tional Family Health Survey (NFHS) dataset conducted in 1998-99, 2005-06, and 2015-16. For the descriptive study, the females residing in the major states of India are taken as the study population. The females are categorized based on their height. The first classification criteria divide females into four groups that are:

1.1 Female having height $\leq 147.0 \mathrm{~cm}$

1.2 Female having height $>147.0 \mathrm{~cm}$ and $\leq 152.0 \mathrm{~cm}$

1.3 Female having height $>152.0 \mathrm{~cm}$ and $\leq 157.0 \mathrm{~cm}$

1.4 Female having height $>157.0 \mathrm{~cm}$

The second criterion is based on the average height of Indian women estimated around $150.0 \mathrm{~cm}$ by the National Institute of Nutrition (2014), which is:

2.1 Female having height $\leq 150.0 \mathrm{~cm}$

2.2 Female having height $>150.0 \mathrm{~cm}$
The literature review suggests many important fertility parameters. Descriptive statistics have been used to get the estimated mean values of selected fertility parameters. The surviving ratio has been estimated to study the relationship between the survival of children and maternal stature. The parity-wise proportion of females is also given for both groups to answer the question of whether parity, the number of previous deliveries, differs by mother's height.

Based on a descriptive study, it is convenient to apply some inferential tools to assess the impact of maternal height on fertility. Since Uttar Pradesh is the most populated and one of the largest states of India, and it is observed that a certain amount of social, ethnic, and regional variability exists within the state itself. Hence, the currently married females aged 15-49 years of Uttar Pradesh have been considered as the study population. Socio-economic and demographic information related to eligible females has been obtained from the fourth round of the National Family Health Survey (2015-16). Since the key study variable in this article is the 'waiting time to the first conception', thus the females have been provided with the exposure of two years after the marriage to get a conception because it is believed that the actual fertility behaviour of females reflects within this period after marriage in Indian traditional societies. Hence the females, who had a marital duration of at least two years at the time of conception, have been considered as the eligible study population. ${ }^{15}$

In this type of estimation, the choice of the predictor variable(s) is very critical and important. An inappropriate choice of a variable may result in not being useful and sometimes we have misleading conclusions. The basic requirement in selecting the variables is that the independent and dependent variable(s) should be highly correlated and data on the independent variable(s) should be easily obtainable.

The above literature review concludes that place of residence, religion, caste, education, age at first marriage, family type, and wealth index; factors have a strong influence on the waiting time to the first conception, especially in Indian traditional society. To give sufficient exposure for getting conception in this study only those females are considered whose marital duration is more than two years. It is worthwhile to mention here that the height of a female is increased up to 16 years of age and after that a little chance of increase in height. Generally, the onset of puberty is the indication of the reproductive maturity of a female. The puberty of females starts around ages 10-11 years and ends around 15-16 years (Kail and Cavanaugh, 2010). Females attain reproductive maturity about 4-5 years after the first onset of physical changes i.e. menarche. Also, puberty is associated with the achievement of maximum height and adult sex hormone levels. Maximum height is achieved on 
an average of about 15-16 years for females and an increase in height beyond pubertal age is exceptional. ${ }^{16}$

Also, females having a waiting time to conception less than or equal to 120 months are considered to avoid recall bias. Thus the final sample size for the study is 40,006 females whose age is more than or equal to 18 years before their first birth (i.e. 17 years at least at the time of conception) along with the information on factors such as place of residence, religion, caste, wealth index, family structure, education level, age at first marriage, and maternal height, which have been considered to influence waiting time to the first conception.

\section{Proposed Predictor}

Besides the previously mentioned factors, some interesting studies suggest that the physical structure of a person may also affect human fertility. The anthropometric measure, which is used basically to measure the growth, development, and health status of a person, may also be considered as a determining factor of fertility. Outside India, there have been quite a few studies that dealt with the correlation between fertility and physical structure ${ }^{12,17-20}$, while in India there is little literature in this context, which attracts the attention of authors to study the relationship between the physical structure of female with fertility. ${ }^{21,22}$ Therefore, authors have coined a suggestion that along with other variables, the height of the female may also influence the waiting time to conception. The average height of the female in Uttar Pradesh is about five feet i.e. $150.0 \mathrm{~cm}$ thus in this study we have categorized the variable height of females into two categories i.e. female height less than or equal to $150.0 \mathrm{~cm}$ and more than 150.0 $\mathrm{cm}$. To know the effect of factors on the duration of waiting time to the first conception, Cox's proportional hazards regression technique has been applied in the present study, and the brief about this technique is discussed below.

\section{Statistical Methods}

\section{Cox's Proportional-hazards Model}

The Cox proportional-hazards model is essentially a regression model commonly used for investigating the association between survival time and one or more predictor variables. ${ }^{23}$ Since in this study females having to wait time to conception less than or equal to 120 months are considered thus the risk of conception in this duration is almost constant and fulfils the basic assumption of the proportional hazard model. The hazard risk function of the first conception at time $t$ due to the hazard regression function is given by

$$
h(t \mid Z)=h_{0}(t) \exp (\beta Z)
$$

Here $h(t \mid Z)$ is the instantaneous risk of having a first conception at time $t$, given that there is no prior conception for a female with $Z$, where $Z$ is a vector of covariates of interest, which may include continuous factors, discrete factors, and possible interactions. $h_{0}(t)$ is a vector of unknown regression co-efficient to be estimated and is an arbitrary nonnegative unspecified baseline hazard function not dependent on the covariates which reflects the underlying hazard for subjects with all covariates $Z_{1}, Z_{2}, \ldots, Z_{p}$ equal to 0 (i.e. the "reference group").

The general form of Cox's PH model is:

$$
h(t \mid Z)=h_{0}(t) \exp \left(\beta_{1} Z_{1}+\beta_{2} Z_{2}+\cdots+\beta_{p} Z_{p}\right)
$$

So when we substitute all of the $Z_{j}$ 's equal to 0 , we get:

$$
h(t \mid Z)=h_{0}(t) \exp \left(\beta_{1} * 0+\beta_{2} * 0+\cdots+\beta_{p} * 0\right)=h_{0}(t)
$$

In the general case, we think of the $i^{\text {th }}$ individual having a set of covariates $Z_{i}=\left(Z_{1 i}, Z_{2 i}, \ldots, Z_{p i}\right)$, and we model their hazard rate as some multiple of the baseline hazard rate:

$$
h_{i}(t)=h\left(t \mid Z_{i}\right)=h_{0}(t) \exp \left(\beta_{1} Z_{1 i}+\beta_{2} Z_{2 i}+\cdots+\beta_{p} Z_{p i}\right)
$$

For two groups where $Z=1$ for the occurrence of an event (first conception) and $Z=0$ non-occurrence of the event. Then $h_{1}(t)$ and $h_{0}(t)$ will be the hazard rate for both groups respectively, such that-

$h_{1}(t)=h(t \mid Z=1)=h_{0}(t) \exp (\beta Z)=h_{0}(t) \exp (\beta)$

$\frac{h_{1}(t)}{h_{0}(t)}=e^{\beta}$

This implies that the ratio of the two hazards is a constant, $e^{\beta}$, which does not depend on time $t$ i.e. the hazards of the two groups remain proportional over time. $e^{\beta}$ is referred to as the hazard ratio or relative risk and $\beta$ is the $\log$ hazard ratio or log relative risk. It becomes unity when no covariate is present, with values greater (or less) than unity indicating the relative risk of having the first conception is greater (or less) for this group than that of the reference group.

This applies to any type of $Z$, as they are the log hazard ratio for one unit increase in the value of $Z$. This means we can write the log of the hazard ratio for $i^{\text {th }}$ the individual to the baseline as:

$$
\log \left\{\frac{h_{i}(t)}{h_{0}(t)}\right\}=\beta_{1} Z_{1 i}+\beta_{2} Z_{2 i}+\cdots+\beta_{p} Z_{p i}
$$

Thus, the Cox Proportional Hazards Model is a linear model for the log of the hazard ratios. In the present study, the set of covariates $Z_{i}=\left(Z_{1 i}, Z_{2 i}, \ldots, Z_{p i}\right)$ for $i^{\text {th }}$ the female is represented by the socioeconomic and demographic factors of females i.e. place of residence, religion, caste, wealth index, family structure, education level, age at first marriage, and height of the female.

\section{RESULTS \& DISCUSSION}

The estimates of fertility indicators i.e. children ever born, survival ratio of children and the proportion of females at 
higher birth order for Indian females are given in Table 1 and Table 2. Table 1 represents the first classification of females based on height where it is found that the mean number of children ever born is decreasing as the maternal height is increasing for all of the three NFHS's. However, the survival ratio of children is relatively high among the taller females as compared to shorter females. The females of shorter height proceed for higher birth order with a greater proportion compared to short females. Similar results have been observed in Table 2 also, where the females are classified into two height groups. Females height less than or equal to $150 \mathrm{~cm}$ have a higher number of children ever born with a lower survival ratio than females height more than $150 \mathrm{~cm}$. Females having a height less than or equal to $150 \mathrm{~cm}$ also tend to go for higher birth order. The results from both tables bear a resemblance with the findings of previous studies conducted for different countries. ${ }^{19,20,24-28}$

As the literature review indicates that few selected socioeconomic and demographic characteristics of females may affect the waiting time to the first conception. Table 3 displays the percentage distribution of females and mean estimates of waiting time to the first conception on the selected socio-demographic indicators. The mean waiting time to the first conception is estimated for non-censored cases i.e. for the females having at least one birth. Here, it can be easily seen that around 70 per cent of females belong to rural areas of Uttar Pradesh and 80 per cent of females belong to the Hindu community. More than half of the eligible females belong to other backward classes while 22.4 per cent of females belong to SC/ST. About half of the female population belongs to an economically poor background. Only 12.8 per cent of females are highly educated and about 41 per cent are illiterate. Another observation reveals that 52.4 per cent of females got married before reaching the legal marriage age i.e. 18 years. 57.1 per cent of females' height is found more than $150.0 \mathrm{~cm}$. The mean waiting time for the first conception is 21.77 months and the standard deviation is 19.67 months, however, the mean waiting time for the first conception in the rural area is around 6 months significantly more compared to urban that indicates urban females conceive earlier than rural females. Waiting time to the first conception for Hindu females is around 5 months significantly longer than for Muslim females. Females who belong to SC/ ST and OBC communities get conception after marriage later than other caste groups significantly. It is observed that as the economic status of females increases, the mean waiting time to get first conception decreases which means females of higher wealth index are getting conceived earlier than lower wealth index females. The waiting time for the first conception is significantly less in females belonging to the joint family (20.82 months) than the female of the nuclear family (22.75 months). The same pattern has been observed in the education level of females. As the level of education increases from illiterate to higher education, the time of getting the first conception is found shorter. It is a very obvious result that the female whose age at first marriage is less than or equal to 18 years having a longer waiting time to the first conception than the females whose age at first marriage is greater than 18 years perhaps younger females are not mature enough to get conception. From this table, the interesting observation about the proposed indicator i.e. maternal height is that the females having a height less than or equal to $150.0 \mathrm{~cm}$ wait about 2.5 months significantly more to conceive in comparison to females having a height greater than $150.0 \mathrm{~cm}$.

Table 4 explains the results of unadjusted Cox's proportional hazard analysis to assess the influence of some selected socio-demographic characteristics on waiting time to the first conception. It shows that urban females have 31.5 per cent more risk to get the first conception earlier as compared to rural females and it is highly significant. If we consider the religion of females then Hindu females are at 20 per cent less risk to get the first conception as compared to Muslim females. The caste of the female has also been taken and it has been observed that other caste females have 14.5 per cent significantly more risk to get conception earlier compared to $\mathrm{SC} / \mathrm{ST}$ females but no significant difference was found in the case of OBC females. The unadjusted Cox's proportional hazards analysis shows that the chance of getting the first conception in the richest, richer, middle, poorer female is significantly high in comparison to the poorest female. If the female belongs to a nuclear family then the risk of getting the first conception is 17 per cent less as compared to a joint family. If we consider the educational status of females then it is observed that as the educational level group is increasing the risk to get the first conception among the females is also increasing. It can be also observed that as the age at first marriage group increases the risk to get the first conception increases significantly. Further, it has also been observed that females with age at marriage more than 18 years have 28.3 per cent more risk for getting the first conception earlier than the female with age at marriage for less than 18 years. Maternal height may also influence the risk of getting the first conception. The result clearly shows that females with a height more than $150 \mathrm{~cm}$ have 11 per cent significantly more risk for getting the first conception earlier than females with a height less than $150 \mathrm{~cm}$.

Table 4 exhibits a summary of eight covariate variables in the unadjusted analysis. It was found that all selected sociodemographic variables have a significant impact on waiting time to the first conception. In table 5, adjusted Cox's proportional hazard analysis is used to assess the variables which have a significant effect on waiting time to the first conception after controlling other socio-demographic variables. There are two models have been created to study the combined effect of selected variables on the waiting time 
to the first conception. In Model I, all variables are considered except the height of the female, and Model II is the full model that considers all variables along with the proposed variable i.e. maternal height. As it is exhibited in Model-I that urban females are at 11 per cent more risk to get the first conception than rural females. Hindu females have around 20 per cent less chance of getting the first conception earlier than Muslim females. Also, the females of backward classes and other communities are about 8 per cent less likely to get the first conception earlier than SC/ST females. It is observed that the waiting time for the first conception of a female is positively associated with the wealth index of the household. The chance of getting the first conception is likely to be more increasing from 8 per cent in poorer to 31 per cent in the richest households' females in comparison to females of the poorest households. Females of the nuclear family are less likely to conceive earlier than females of the joint family due to a lack of social taboos in a joint family. Education also plays an important role in the reproduction process and it is observed that the females who are primary and secondary educated are likely to have a 12 per cent more chance of getting earlier their first conception than illiterate females. Higher educated females have about 3 per cent more chance of getting their first conception than the illiterate ones but it is insignificant. This may be caused due to large variability in the waiting time of the first conception. Some of the educated females don't want to wait much after marriage but some wait some time due to the pressure of their nature of job or involvement to a higher degree. Since it is known that the females who have got married in later years; usually get an early conception because of their physical and mental maturity and also they have the will of getting a child due to increasing age insecurity. Thus, the females whose age at first marriage is more than 18 years; are a 22 per cent more chance of getting the first conception. All the predictor variables show the statistically significant chance for waiting time to the first conception. Now a new predictor variable i.e. maternal height has been added to the ModelII. It is observed that all the previous predictor variables are also statistically significant with the almost same chance for waiting time to the first conception as well as for the new predictor variable. The females who have height more than average height i.e. $150.0 \mathrm{~cm}$; have a 6 per cent more chance of getting the first conception earlier than the females having a height less than or equal to $150.0 \mathrm{~cm}$.

In the adjusted model, all the predictor variables contribute to maximizing the log-likelihood of the model. The reduction in -2LL is observed in model-II indicates the height of the female is an important predictor of waiting time. Thus, Model-II provides a better explanation of the waiting time to the first conception and the proposed predictor in model-II i.e. maternal height shows a significant impact on the waiting time to the first conception of females.

\section{CONCLUSION}

In the context of Indian society, fertility is regulated through various determining factors but when it is talked about the first birth i.e. starting of parenthood, these intermediate variables have less impact on reproductive behaviour. Since it is almost free from contraceptive use, the socio-demographic factors such as religion, caste, economic status of the household, education level of female, household structure, and female's age at marriage, play a significant role in determining the waiting time for the first conception. The present study stands upon its objective and concludes that the physical structure of females also has an impact on waiting time to the first conception along with the other socio-demographic factors and it may change females' reproductive behaviour. It is observed that the waiting time for the first conception is significantly associated with the height of females. Taller females are at more risk to get the first conception than shorter females. Hence the proposed factor, maternal height may be considered as a determining factor in future studies concerned about the waiting time to the first conception.

\section{Conflict of Interest: None.}

Funding Information: None.

\section{ACKNOWLEDGEMENT}

We are thankful to the anonymous reviewer(s) of this article for providing insightful comments and providing directions for additional work which has resulted in this paper.

\section{Authors' Contribution Details:}

Prof. A K Tiwari and Prof. Brijesh P Singh were responsible for the development of the concept and design of this study. Statistical Models and their interpretations were established by Prof. Brijesh P Singh. Writing the manuscript was done by Shivam Mishra and Prof. A K Tiwari contributed to revising the manuscript critically and approved the final version.

\section{REFERENCES}

1. Kalan J, Udry JR. The Determinant of Effective Fecundability Based on the First Birth Interval. Demography 1986; 23(1):5366.

2. Rao VK. Demographic Models for Age at First Marriage and First Birth: An application of Canadian data. $\mathrm{PhD}$ thesis, University of Western Ontario, London, Canada; 1987.

3. Rao KV, Balakrishnan TR. Age at First Birth in Canada: A Hazard Model Analysis. Genus 1988;44(1):55-72.

4. Singh, Suchindran CM, Singh V, Ramakumar R. Age at Return Marriage and Timing of First Birth in India's Uttar Pradesh and the Kerala States. Soc Biol 1992;39:292-298.

5. Nath DC, Singh KK, Land KC, Talukdar PK. Age of Marriage and Length of the First Birth Interval in a Traditional Society: Life Table and Hazards Model Analysis. Hum Biol 1993;65:783797. 
6. Mukherjee S, Bhattacharya BN, Singh KK. Distribution of Time of First Birth in Presence of Social Customs Regulating Physical Separation and Coital Frequency. Math Biosci 1994;31:1-21.

7. Nath DC. Family Planning and Assamese Women. The North East Times 1995;6(55).

8. Hoque F, Khan MSH, Haque A. Levels, Trends and Determinants of Fecundability in Bangladesh: A Comparative Study Using Bangladesh Health and Demographic Survey (BDHS) Data. 2012;379-389.

9. Singh BP, Singh G, Singh KK. Heterogeneity in Waiting Time to First Conception in Uttar Pradesh: A Parametric Regression Analysis. Demography India 2016;45(1/2):77-88.

10. Nath DC, Singh KK, Talukdar PK. Most Recent Birth Intervals in a Traditional Society: A Life Table and Hazards Regression Analysis. Can Stud Popul 1994;21(2):149-164.

11. Nath DC, Land KC, Goswami G. Effect of the Status of Women on the First Birth Interval in Indian Urban Society. J Biosoc Sci 1999;31:55-59.

12. Davenport CB. Body Build and Its Inheritance. Washington DC: Carnegie Institution Press; 1923.

13. Clark P, Spuhler JN. Differential fertility about body dimensions. Hum Biol 1959;31:121-137.

14. Bajema CJ. Estimation of the direction and intensity of natural selection about height, weight and ponderal index: a follow-up study of Third Harvard Growth Study participants. IX International Congress of Anthropological and Ethnological Sciences; 1973; Chicago, USA.

15. International Institute for Population Sciences (IIPS) and ICF. National Family Health Survey (NFHS-4), 2015-16. Mumbai: IIPS; 2017.

16. World Health Organization (WHO). Child Growth Standards: length/height-for-age, weight-for-age, weight-for-length, weight-for-height and body mass index-for-age: methods and development. Geneva: WHO; 2006.
17. Mitton JB. Fertility differentials in modern societies result in normalizing selection for height. Hum Biol 1975;49:189-200.

18. Vetta A. Fertility, physique and intensity of selection. Hum Biol 1975;47:283-293.

19. Martorell R, Delgado HL, Delgado H, Valverde V, Klein RE. Maternal stature, fertility and infant mortality. Hum Biol 1981;53(3):303-12.

20. Sear R, Allal N, McGregor IA, Mace R. Height, marriage and reproductive success in Gambian women. Res Econ An 2004;23:203-24.

21. Tiwari K. Fertility and Physique of Muslim Women of East Nimar [dissertation].New Delhi: Delhi Univ.; 1974.

22. Malik S. Fertility and body dimensions: a study among the Rajputs of Benjiwari village, District Pauri Garhwal. Indian Anthropologist 1992;22(2):15-29.

23. Cox DR. Regression Models and Life Tables (with discussion). J R Stat Soc B 1972;34:184-220.

24. Bernard RM. The shape and size of the female pelvis. Edinb Med J 1952;59:2-16.

25. Bressler JB. Maternal height and the prevalence of stillbirths. Am J Phys Anthropol 1962;20:515-517.

26. Subramanian SV, Ackerson LK, Smith GD, John NA. Association of Maternal Height with Child Mortality, Anthropometric Failure, and Anemia in India. J Am Med Assoc 2009;301(16):1691-1701.

27. Ozaltin E, Hill K, Subramanian SV. Association of Maternal Stature with Offspring Mortality, Underweight, and Stunting in Low- to Middle-Income Countries. J Am Med Assoc 2010;303(15):1507-1516.

28. Khatun W, Ashraful A, Sabrina R, Tanvir MH, DibleyMJ. Exploring the intergenerational effects of undernutrition: association of maternal height with neonatal, infant and under-five mortality in Bangladesh. BMJ Global Health 2018:1-12.

Table 1: Mean Estimates of Fertility Indicators for the Indian Females (Classification 1)

\begin{tabular}{|c|c|c|c|c|}
\hline \multirow{2}{*}{$\begin{array}{l}\text { Survey } \\
\text { Data }\end{array}$} & \multirow{2}{*}{ Females having height } & \multicolumn{3}{|c|}{ Fertility Parameters } \\
\hline & & CEB & SR & $\mathrm{BO}_{3}$ \\
\hline \multirow{4}{*}{ NFHS-II (1998-99) } & $\leq 147.0 \mathrm{~cm}$ & 3.44 & 0.880 & 0.619 \\
\hline & $147.1-152.0 \mathrm{~cm}$ & $3 \cdot 35$ & 0.898 & 0.604 \\
\hline & $152.0-157.0 \mathrm{~cm}$ & 3.28 & 0.911 & 0.589 \\
\hline & $>157.0 \mathrm{~cm}$ & 3.09 & 0.924 & 0.547 \\
\hline \multirow{4}{*}{ NFHS-III (2005-06) } & $\leq 147.0 \mathrm{~cm}$ & 3.18 & 0.899 & 0.565 \\
\hline & $147.1-152.0 \mathrm{~cm}$ & 3.08 & 0.921 & 0.546 \\
\hline & $152.0-157.0 \mathrm{~cm}$ & 2.98 & 0.932 & 0.520 \\
\hline & $>157.0 \mathrm{~cm}$ & 2.79 & 0.943 & 0.463 \\
\hline \multirow{4}{*}{ NFHS-IV (2015-16) } & $\leq 147.0 \mathrm{~cm}$ & 2.97 & 0.927 & 0.533 \\
\hline & $147.1-152.0 \mathrm{~cm}$ & 2.82 & 0.945 & 0.490 \\
\hline & $152.0-157.0 \mathrm{~cm}$ & 2.69 & 0.954 & 0.453 \\
\hline & $>157.0 \mathrm{~cm}$ & 2.51 & 0.962 & 0.395 \\
\hline
\end{tabular}

Note: $\mathrm{CEB}=$ Children ever born to female

$\mathrm{SR}=$ Survival ratio of children

$\mathrm{BO}_{3}=$ Proportion of females having 3 or more birth order children 
Table 2: Mean Estimates of Fertility Indicators for the Indian Females (Classification 2)

\begin{tabular}{lcccc}
$\begin{array}{l}\text { Survey } \\
\text { Data }\end{array}$ & Females having height & \multicolumn{3}{c}{ Fertility Parameters } \\
NFHS-II (1998-99) & $\leq 150.0 \mathrm{~cm}$ & CEB & SR & $\mathbf{B O}_{3}$ \\
& $>150.0 \mathrm{~cm}$ & 3.42 & 0.886 & 0.615 \\
NFHS-III (2005-06) & $\leq 150.0 \mathrm{~cm}$ & 3.24 & 0.912 & 0.581 \\
& $>150.0 \mathrm{~cm}$ & 3.15 & 0.908 & 0.560 \\
NFHS-IV (2015-16) & $\leq 150.0 \mathrm{~cm}$ & 2.95 & 0.933 & 0.509 \\
& $>150.0 \mathrm{~cm}$ & 2.91 & 0.934 & 0.517 \\
\hline
\end{tabular}

Note: $\mathrm{CEB}=$ Children ever born to female

$\mathrm{SR}=$ Survival ratio of children

$\mathrm{BO}_{3}=$ Proportion of females having 3 or more birth order children

Table 3: Descriptive statistics on some socio-demographic characteristics of females

\begin{tabular}{|c|c|c|c|c|c|}
\hline \multirow[t]{2}{*}{ Variables } & & \multirow[t]{2}{*}{ Percent } & \multicolumn{2}{|c|}{$\begin{array}{l}\text { Waiting time to first conception } \\
\text { (in months)* }\end{array}$} & \multirow[t]{2}{*}{$\begin{array}{l}\text { Test for equality of } \\
\text { means }\end{array}$} \\
\hline & & & Mean & St. Deviation & \\
\hline \multirow[t]{2}{*}{ Place of residence } & Rural & 69.8 & 23.57 & 20.357 & \multirow{2}{*}{$\begin{array}{l}\mathrm{t}=28.86 \\
\mathrm{p}=0.000\end{array}$} \\
\hline & Urban & 30.2 & 17.59 & 17.255 & \\
\hline \multirow[t]{2}{*}{ Religion } & Hindu & 80.1 & 22.77 & 20.078 & \multirow{2}{*}{$\begin{aligned} \mathrm{t} & =21.65 \\
\mathrm{p} & =0.000\end{aligned}$} \\
\hline & Muslim & 19.9 & $17 \cdot 70$ & $17 \cdot 326$ & \\
\hline \multirow[t]{3}{*}{ Caste } & $\mathrm{SC} / \mathrm{ST}$ & 22.4 & 22.59 & 19.891 & \multirow{3}{*}{$\begin{array}{l}F=62.02 \\
p=0.000\end{array}$} \\
\hline & OBC & 54.2 & 22.31 & 19.898 & \\
\hline & Others & 23.4 & 19.72 & 18.753 & \\
\hline \multirow[t]{5}{*}{ Wealth index } & Poorest & 22.3 & 26.80 & 21.785 & \multirow{5}{*}{$\begin{array}{l}F=326.81 \\
P=0.000\end{array}$} \\
\hline & Poorer & 21.4 & 24.16 & 20.496 & \\
\hline & Middle & 18.6 & 21.11 & 19.040 & \\
\hline & Richer & 17.5 & 18.81 & 17.702 & \\
\hline & Richest & 20.2 & 16.91 & 16.619 & \\
\hline \multirow[t]{2}{*}{ Family structure } & Nuclear & 50.6 & 22.75 & 20.043 & \multirow{2}{*}{$\begin{aligned} t & =9.45 \\
p & =0.000\end{aligned}$} \\
\hline & Joint & 49.4 & 20.82 & 19.250 & \\
\hline \multirow[t]{4}{*}{ Educational level } & Illiterate & 40.7 & 25.27 & 21.343 & \multirow{4}{*}{$\begin{array}{l}F=305.56 \\
p=0.000\end{array}$} \\
\hline & Primary & 13.0 & 21.10 & 18.911 & \\
\hline & Secondary & 33.5 & 19.30 & 17.977 & \\
\hline & Higher & 12.8 & 17.47 & 16.865 & \\
\hline \multirow[t]{2}{*}{ Age at first marriage } & $\leq 18$ years & 52.4 & 25.08 & 20.835 & \multirow{2}{*}{$\begin{aligned} t & =35.12 \\
p & =0.000\end{aligned}$} \\
\hline & $>18$ years & 47.6 & 18.05 & 17.537 & \\
\hline \multirow[t]{2}{*}{ Maternal height } & $\leq 150.0 \mathrm{~cm}$ & 42.9 & 23.07 & 20.468 & $t=10.90$ \\
\hline & $>150.0 \mathrm{~cm}$ & 57.1 & 20.79 & 18.987 & $\mathrm{p}=0.000$ \\
\hline Total & & 100.0 & 21.77 & 19.67 & - \\
\hline
\end{tabular}

*Calculated for the females having at least one birth 
Table 4: Unadjusted Cox's proportional hazards analysis for the impact of socio-demographic variables on waiting time to the first conception

\begin{tabular}{|c|c|c|c|c|}
\hline \multirow[t]{2}{*}{ Variables } & \multirow[t]{2}{*}{ Hazard Ratio } & \multirow[t]{2}{*}{ p-value } & \multicolumn{2}{|c|}{$95 \%$ Confidence interval } \\
\hline & & & Lower & Upper \\
\hline \multicolumn{5}{|c|}{ Place of residence $^{1}$} \\
\hline Urban & 1.315 & 0.000 & 1.285 & 1.344 \\
\hline \multicolumn{5}{|l|}{ Religion $^{2}$} \\
\hline Hindu & 0.795 & 0.000 & 0.775 & 0.816 \\
\hline \multicolumn{5}{|l|}{ Caste $^{3}$} \\
\hline OBC & 1.018 & 0.185 & 0.992 & 1.044 \\
\hline Others & 1.145 & 0.000 & 1.111 & 1.180 \\
\hline \multicolumn{5}{|c|}{ Wealth index ${ }^{4}$} \\
\hline Poorer & 1.120 & 0.000 & 1.086 & 1.155 \\
\hline Middle & 1.252 & 0.000 & 1.213 & 1.293 \\
\hline Richer & 1.398 & 0.000 & 1.353 & 1.445 \\
\hline Richest & 1.563 & 0.000 & 1.515 & 1.613 \\
\hline \multicolumn{5}{|c|}{ Family structure 5} \\
\hline Nuclear & 0.827 & 0.000 & 0.811 & 0.845 \\
\hline \multicolumn{5}{|c|}{ Educational level $^{6}$} \\
\hline Primary & 1.150 & 0.000 & 1.113 & 1.188 \\
\hline Secondary & 1.219 & 0.000 & 1.190 & 1.249 \\
\hline Higher & 1.268 & 0.000 & 1.227 & 1.311 \\
\hline \multicolumn{5}{|c|}{ Age at first marriage $^{7}$} \\
\hline$>18$ years & 1.283 & 0.000 & 1.257 & 1.310 \\
\hline \multicolumn{5}{|c|}{ Maternal height ${ }^{8}$} \\
\hline$>150.0 \mathrm{~cm}$ & 1.110 & 0.000 & 1.087 & 1.133 \\
\hline
\end{tabular}

Reference category- 1: Rural, 2: Muslim, 3: SC/ST, 4: Poorest, 5: Joint, 6: Illiterate, 7: $\leq 18$ years, 8: $\leq 150.0 \mathrm{~cm}$

Table 5: Adjusted Cox's proportional hazards analysis for the impact of socio-demographic variables on waiting time to the first conception

\begin{tabular}{|c|c|c|c|c|c|c|c|c|}
\hline \multirow{3}{*}{ Variables } & \multicolumn{4}{|c|}{ Model-I } & \multicolumn{4}{|c|}{ Model-II } \\
\hline & \multirow{2}{*}{$\begin{array}{l}\text { Hazard } \\
\text { Ratio }\end{array}$} & \multirow{2}{*}{ p-value } & \multicolumn{2}{|c|}{$\begin{array}{l}95 \% \text { Confidence } \\
\text { Interval }\end{array}$} & \multirow{2}{*}{$\begin{array}{l}\text { Hazard } \\
\text { Ratio }\end{array}$} & \multirow{2}{*}{ p-value } & \multicolumn{2}{|c|}{$\begin{array}{l}95 \% \text { Confidence } \\
\text { Interval }\end{array}$} \\
\hline & & & Lower & Upper & & & Upper & Lower \\
\hline \multicolumn{9}{|c|}{ Place of residence $^{1}$} \\
\hline Urban & 1.112 & 0.000 & 1.082 & 1.143 & 1.116 & 0.000 & 1.085 & 1.147 \\
\hline \multicolumn{9}{|l|}{ Religion $^{2}$} \\
\hline Hindu & 0.806 & 0.000 & 0.783 & 0.829 & 0.808 & 0.000 & 0.786 & 0.831 \\
\hline \multicolumn{9}{|l|}{ Caste $^{3}$} \\
\hline $\mathrm{OBC}$ & 0.920 & 0.000 & 0.896 & 0.945 & 0.918 & 0.000 & 0.894 & 0.943 \\
\hline Others & 0.927 & 0.000 & 0.897 & 0.958 & 0.923 & 0.000 & 0.893 & 0.954 \\
\hline \multicolumn{9}{|c|}{ Wealth index ${ }^{4}$} \\
\hline Poorer & 1.079 & 0.000 & 1.045 & 1.114 & 1.077 & 0.000 & 1.044 & 1.112 \\
\hline Middle & 1.159 & 0.000 & 1.120 & 1.199 & 1.154 & 0.000 & 1.116 & 1.195 \\
\hline Richer & 1.228 & 0.000 & 1.183 & 1.275 & 1.220 & 0.000 & 1.175 & 1.267 \\
\hline Richest & 1.306 & 0.000 & 1.252 & 1.362 & 1.294 & 0.000 & 1.240 & 1.350 \\
\hline
\end{tabular}


Table 5: (Continued)

\begin{tabular}{|c|c|c|c|c|c|c|c|c|}
\hline \multirow{3}{*}{ Variables } & \multicolumn{4}{|c|}{ Model-I } & \multicolumn{4}{|c|}{ Model-II } \\
\hline & \multirow{2}{*}{$\begin{array}{l}\text { Hazard } \\
\text { Ratio }\end{array}$} & \multirow{2}{*}{ p-value } & \multicolumn{2}{|c|}{$\begin{array}{l}95 \% \text { Confidence } \\
\text { Interval }\end{array}$} & \multirow{2}{*}{$\begin{array}{l}\text { Hazard } \\
\text { Ratio }\end{array}$} & \multirow{2}{*}{ p-value } & \multicolumn{2}{|c|}{$\begin{array}{l}95 \% \text { Confidence } \\
\text { Interval }\end{array}$} \\
\hline & & & Lower & Upper & & & Upper & Lower \\
\hline \multicolumn{9}{|l|}{ Family structure $^{5}$} \\
\hline Nuclear & 0.840 & 0.000 & 0.823 & 0.858 & 0.840 & 0.000 & 0.823 & 0.898 \\
\hline \multicolumn{9}{|l|}{ Educational level $^{6}$} \\
\hline Primary & 1.115 & 0.000 & 1.079 & 1.152 & 1.114 & 0.000 & 1.078 & 1.151 \\
\hline Secondary & 1.122 & 0.000 & 1.092 & 1.152 & 1.118 & 0.000 & 1.088 & 1.148 \\
\hline Higher & 1.027 & 0.178 & 0.988 & 1.068 & 1.020 & 0.326 & 0.981 & 1.061 \\
\hline \multicolumn{9}{|c|}{ Age at first marriage ${ }^{7}$} \\
\hline$>18$ years & 1.220 & 0.000 & 1.194 & 1.246 & 1.220 & 0.000 & 1.195 & 1.247 \\
\hline \multicolumn{9}{|l|}{ Maternal height $^{8}$} \\
\hline$>150.0 \mathrm{~cm}$ & - & - & - & - & 1.060 & 0.000 & 1.038 & 1.083 \\
\hline -2 Log Likelihood & \multicolumn{4}{|c|}{709841.301} & \multicolumn{4}{|c|}{709811.343} \\
\hline
\end{tabular}

Reference category- 1: Rural, 2: Muslim, 3: SC/ST, 4: Poorest, 5: Joint, 6: Illiterate, 7: $\leq 18$ years, 8: $\leq 150.0 \mathrm{~cm}$ 